\title{
LAPAROSCOPIC VENTRAL HERNIA: A PROSPECTIVE STUDY
}

\author{
Amit Goel ${ }^{1}$
}

${ }^{1}$ Associate Professor and Consultant Surgeon, Department of Surgery, Jamia Hamdard Medical College, Delhi.

\begin{tabular}{l} 
ABSTRACT \\
\hline OBJECTIVE \\
Ventral hernias are repaired either by open or laparoscopic approach. Laparoscopic hernia repair provides early recovery and \\
bigger mesh to be placed.
\end{tabular}

\section{STUDY DESIGN}

Patients evaluated between January 2014 and September 2015 for ventral hernias. Laparoscopic surgery was performed for 12 patients.

\section{RESULTS}

Laparoscopic ventral hernia repair was performed for 12 patients. There were conversions for adhesions.

\section{CONCLUSION}

Laparoscopic hernia surgery is effective repair with early recovery and lesser adhesions. The composite meshes are better for laparoscopic repair.

\section{KEYWORDS}

Hernia, Ventral, Mesh, Repair.

HOW TO CITE THIS ARTICLE: Goel A. Laparoscopic ventral hernia: a prospective study. J. Evolution Med. Dent. Sci. 2016;5(46): 2946-2947, DOI: $10.14260 /$ jemds/2016/686

\section{INTRODUCTION \\ Laparoscopic hernia repair is an intra-abdominal, intra- peritoneal repair that uses mesh prosthesis to secure and cover the hernia defect. Abdominal hernias are equally assessable by laparoscopic and open surgery. Fascial defects 3 $\mathrm{cm}$ larger are amenable for laparoscopic approach and less than $3 \mathrm{~cm}$ amenable for open surgery. Laparoscopic repair of incisional hernias and ventral hernias was performed in 1993 by Le Blanc. ${ }^{1}$}

\section{MATERIAL AND METHODS}

Patients were evaluated for abdominal hernias between January 2014 and September 2015; 22 cases of abdominal hernias were admitted in our unit. Open surgery was performed in 6 patients. Intraperitoneal repair was performed for 12 patients; 4 patients were managed conservatively. For majority of patients, prolene mesh was placed. PTFE mesh was placed in 3 patients. Mesh was secured by transabdominal four corner sutures and tackers. Wound infection was present in 3 patients, seroma in 4 patients. Recurrences were nil. One patient developed bowel injury, which was subsequently repaired intraoperatively. There were 6 patients of recurrent hernias, one patient of port site hernia and one patient of hernia occurring at peripheral drain site. After entering the abdomen from palmer's point, trocars are placed laterally and small intestine and omental adhesions are reduced. Mesh is placed with $3 \mathrm{~cm}$ margin from defect each side and prolene

Financial or Other, Competing Interest: None.

Submission 21-04-2016, Peer Review 19-05-2016,

Acceptance 24-05-2016, Published 09-06-2016.

Corresponding Author:

Dr. Amit Goel,

\#513/514, $1^{\text {st }}$ Floor, Double Storey,

New Rajinder Nagar, New Delhi.

E-mail: gamit11@rediffmail.com

DOI: $10.14260 /$ jemds/2016/686 mesh is placed. There was followup of 7 months for patients post-operatively and commonest complication was seroma diagnosed by ultrasound.

\section{DISCUSSION}

Abdominal hernias in midline, in upper and lower quadrants are equally accessible by laparoscopic approach. Multiple operated patients, extent and density of adhesions are main determinants of operative time and difficulty of laparoscopic ventral hernias repair. Patients with multiple defects were laparoscopic hernia repair that delineates the defect for mesh to be placed. Contraindications of laparoscopic approach are densely scarred and strangulated hernias. Prolene meshes cause parietal ingrowth, which repairs and strengthens the hernia repair. ${ }^{2}$ The risk of patients is potential for development of significant adhesions for using polypropylene mesh for hernia repair. Franklin study showed that only $1 / 3$ of re-operated patients have no adhesions. ${ }^{3}$

Dual meshes have rough parietal surface and smooth visceral surface form lesser adhesions. Few dual meshes are impregnated with silver and chlorhexidine antimicrobial agents which decrease the risk of infection, reduces the glare of prosthesis when used laparoscopically have been effective for repair of incisional hernias. ${ }^{4}$

The composite meshes have polypropylene attached with thin layer of e-PTFE. The Parietex and Parietene composite products combine polyester and polypropylene biomaterials and oxidized atelocollagen, polyethylene glycol and glycerol. The collagen is absorbed within 14 days. Glucamesh has products without collagen which is absorbed, preventing intra-abdominal infections. The intent of biomaterials is the native collagen of patient which penetrates and replaces collagen fibrils, neofascia created to repair the defect. The majority of surgeons use transfascial sutures and metal fixation devices.

The defect should have larger overlap of prosthetic biomaterial and utilize double crown technique placing 
concentric rows of tacks along periphery of dual mesh reduced recurrence to $4.4 \% .^{5}$ Suture fixation was stronger with tacks, and addition of transfascial sutures with tacks should be preferred. 6

The development of seroma is common after this procedure and fluid secreted by peritoneal membrane surface will result in a fluid collection that will be contained by prosthetic biomaterial. Seromas are not complications unless fluid collection persists for longer than 8 weeks and associated with pain. The use of abdominal binders reduced seromas significantly. Seromas resolve within 12 weeks and should not be aspirated unless patient remains symptomatic for longer than 6 months. The application of harmonic scalpel with central suture reduced recurrence rate to $5 \% .{ }^{7}$

\section{CONCLUSION}

The advantages of laparoscopic ventral hernia repair are cosmesis, early return to work. Multiple and peripheral defects could be visualized and repaired by placing larger mesh. Laparoscopic ventral hernia repair is an effective method of repair for hernias with defect larger than $3 \mathrm{~cm}$. Biomaterial should be used that cause sufficient ingrowth. Fixation of these biomaterials should use transfascial sutures with addition of metal fixation devices. Seromas should be managed expectantly.

\section{REFERENCES}

1. Leblanc KA, Booth WV. Laparoscopic repair of incisional abdominal hernias using expanded polytetrafluroethylene: preliminary findings. Surg Laparosc Endosc 1993;3(1):39-41.

2. Chowbey PK, Sharma A, Khullar R. Laparoscopic ventral hernia repair. Surgical endoscopy 1993;3:39-41.

3. Franklin ME, Dorman JP, Glass JL, et al. Laparoscopic ventral and incisional hernia repair. Surg Laparosc Endosc 1998;8(4):294-9.

4. LeBlanc KA, Whitaker JM, Bellanger DE, et al. Laparoscopic incisional and ventral hernioplasty, lessons learned from 200 patients. Hernia 2003;7(3):118-24.

5. Carbago MA, Martin Del, Omlo JP, et al. Laparoscopic approach to incisional hernia. Surg Endosc 2003;17(1):118-22.

6. Van T, Riet M, Devosvan, et al. Tensile strength of mesh fixation methods in laparoscopic incisional hernia repair. Surg Endosc 2002;16(12):1713-6.

7. Tsimoyianni EG, Siakas P, Glantzonissis, et al. Seromas in laparoscopic ventral hernioplasty. Surg Endosc 2003;17:123-8. 